\title{
Effect of hourly concentration of particulate matter on peak expiratory flow in hospitalized children: A panel study
}

Shin Yamazaki ${ }^{*}$, Masayuki Shima ${ }^{2}$, Michiko Ando $^{3}$, Hiroshi Nitta ${ }^{4}$,Hiroko Watanabe ${ }^{5}$, Toshiyuki Nishimuta ${ }^{5}$

\begin{abstract}
Background: Little information is available on the possible association between hourly short-term air pollution and peak expiratory flow (PEF) in asthmatic children.

Methods: PEF was measured twice daily, from October through December, 2000, in 17 children aged 8 to 15 years hospitalized with severe asthma. A total of 1198 PEF measurements were made at 7 a.m. and 1175 at 7 p.m. Measurements were conducted immediately prior to medication under the guidance of trained nurses. PEF changes were estimated in $10-\mu \mathrm{g} / \mathrm{m}^{3}$ increments of particulate matter with a $50 \%$ cut-off aerodynamic diameter of $\leq 2.5 \mu \mathrm{m}\left(\mathrm{PM}_{2.5}\right)$, with adjustment for sex, age, height, and temperature. Lagged-hour exposures of up to 24 hours were examined.
\end{abstract}

Results: Increased 24-hour mean concentration of $\mathrm{PM}_{2.5}$ was associated with a decrease in both morning and evening PEF (-3.0 I/minute; 95\%Cl: $-4.6,-1.4$ and $-4.4 \mathrm{I} /$ minute; $95 \% \mathrm{Cl}:-7.1,-1.7$, respectively). In addition, hourly concentrations of $\mathrm{PM}_{2.5}$ and PEF showed a significant association between some lags of $\mathrm{PM}_{2.5}$ and PEF. Effect size was almost $-3 \mathrm{l} /$ minute in both morning and evening PEF for an hourly $\mathrm{PM}_{2.5}$ concentration of $10 \mathrm{\mu g} / \mathrm{m}^{3}$ in several lags. Even after adjustment for other air pollutants, some of the significant associations with PEF remained.

Conclusion: Among hospitalized children with severe asthma, increased hourly concentration of $\mathrm{PM}_{2.5}$ was associated with a decrease in PEF.

\section{Background}

Numerous studies across various environmental conditions have indicated the acute impact of ambient air pollution on human health [1]. In particular, elevated concentrations of particulate matter (PM) are associated with an increased incidence of respiratory symptoms and decreased lung function $[1,2]$. Children are considered to be more sensitive to air pollution than adults $[3,4]$. Environmental causes of asthma are usually related to climatic conditions that promote appreciable concentrations of atmospheric pollutants and antigens, and while any exposed individual in the general population may develop respiratory symptoms, the effect appears to more severe in those with pre-existing asthma or other respiratory diseases. Evidencing this, sensitivity to

\footnotetext{
* Correspondence: yamazaki.shin@kt8.ecs.kyoto-u.ac.jp

'Department of Epidemiology and Healthcare Research, Kyoto University

School of Public Health, Yoshidakonoe-cho, Sakyo-ku, Kyoto, Japan

Full list of author information is available at the end of the article
}

ambient PM differs between asthmatic and non-asthmatic children. Further, decrement of peak expiratory flow (PEF) in asthmatic children is associated with increased daily concentrations of PM [1]. In contrast, findings for the association between daily concentrations of PM and PEF in non-asthmatic children have been inconsistent, with few studies reporting results similar to those in asthmatic children [1].

Although asthmatic children appear more sensitive to PM than non-asthmatic children, the effect of transiently high concentrations of PM on PEF in these children remains unclear. Transiently high concentrations have been observed from hourly data, but not from daily data [5]. To identify possible associations between hourly short-term air pollution and PEF, we analyzed hourly air pollution and PEF data noted in the medical records of children hospitalized with asthma.

\section{() Biomed Central}




\section{Methods \\ Subjects}

The subjects of this panel study were 17 children aged 8 to 15 years who had been physician-diagnosed with severe asthma and were hospitalized at Shimoshizu National Hospital, Yotsukaido City, Japan. Yotsukaido City is located east of the greater Tokyo metropolitan area, within 40 kilometers of central Tokyo. This national hospital was established as a sanatorium in 1897, and is presently used primarily to provide long-term medical treatment. No major roads or factories are present in the vicinity of the hospital. Its large premises include a school for sick children adjacent to the hospital. Because the children had poorly controlled asthma with frequent exacerbations, they were under long-term hospitalization for maintenance of asthma medication and therefore attended the school. They are permitted to go outside when their condition is stable. All of the subjects had an atopic disposition and received asthma medication, including inhaled corticosteroids. In October 2000, informed written consent was obtained from all the subjects and their parents. The study was approved by the Medical Ethics Committee of Shimoshizu National Hospital.

\section{Outcome measurement}

PEF was evaluated twice daily in all children using an electronic spirometer (AS-300; Minato Medical Inc., Tokyo, Japan). Measurements were conducted at 7 a.m. and 7 p.m., immediately prior to medication, under the guidance of trained nurses. PEF data were collected from October 1, 2000 through December 24, 2000. PEF was monitored to assess the efficacy of treatment for asthma. Because the children did not usually exhale from full inspiration to the maximal expiratory position, parameters such as forced expiratory volume in one second or forced vital capacity were not regularly recorded.

\section{Exposure assessment}

Hourly concentrations of PM with a 50\% cut-off aerodynamic diameter of $\leq 2.5 \mu \mathrm{m}\left(\mathrm{PM}_{2.5}\right)$ were measured using an R\&P TEOM-1400 (Rupprecht \& Patashnick Co. Inc., Albany, NY) located at a monitoring station next to the hospital, at residential area. Data on hourly concentrations of nitrogen dioxide $\left(\mathrm{NO}_{2}\right)$ and photochemical oxidants $(\mathrm{Ox})$ measured at the monitoring station were obtained from the Chiba Prefectural Government. Local temperature data were obtained from the Japan Meteorological Agency. Concentrations of $\mathrm{NO}_{2}$ were measured by colorimetry using the Saltzman reagent method, while those of Ox were measured by absorption spectrophotometry using a neutral potassium iodide solution method according to guidelines of the Japanese Ministry of Environment. It is recognized that concentrations of $\mathrm{Ox}$ are nearly equivalent to those of ozone.

\section{Statistical methods}

The association between hourly concentration of air pollutants and PEF was analyzed used Generalized Estimating Equations (GEE) [6]. We estimated the change in PEF by $10-\mu \mathrm{g} / \mathrm{m}^{3}$ increments in $\mathrm{PM}_{2.5}$ with adjustment for sex, age, height at baseline survey, temperature at the time PEF was measured, day of the week and temporal trends (single-pollutant model). This basic model included sex, age, height and confounders selected on the basis of previous findings. We also estimated the change in PEF by $10-\mu \mathrm{g} / \mathrm{m}^{3}$ increments in $\mathrm{PM}_{2.5}$ adjusted for hourly concentration of $\mathrm{Ox}$, which was measured at the same time as $\mathrm{PM}_{2.5}$, and the variables described above (2-pollutant model), and adjusted for hourly concentrations of $\mathrm{NO}_{2}$ and $\mathrm{Ox}$ measured at the same time as $\mathrm{PM}_{2.5}$, as well as the variables above (3-pollutant model). Lagged-hour exposures of up to 24 hours were examined. For example, lag 12 for the PEF measured at 7 a.m. referred to the concentration of air pollutants during the period from 6 to 7 p.m. on the previous day, and lag 0 referred to the period from 6 to 7 a.m. on the same day. We also estimated previous 24-hour mean concentrations of air pollutants and PEF. Moreover, we also examined other air pollutants such as $\mathrm{NO}_{2}$ and $\mathrm{Ox}$ and PEF using a single-pollutant model and a 3-pollutant model.

Associations were estimated by GEE using the GENMOD procedure of SAS release 9.1 (SAS Institute, Inc., Cary, NC, USA). All tests were two-tailed, and alpha was set at 0.05. Changes in PEF and their 95\% confidence intervals (CIs) were estimated.

\section{Results}

Among the 17 asthmatic children, 1198 PEF measurements were conducted at 7 a.m. and 1175 at 7 p.m., giving an average of 70 morning and 69 evening measurements per child (Table 1). Table 1 also shows mean, minimum, and maximum PEF of each subject. Hourly mean concentrations of air pollutants at 7 a.m., 1 p.m., 7 p.m., and 1 a.m. are shown in Table 2. Correlations among these air pollutants are shown in Table 3. A longitudinal chart of hourly concentrations of $\mathrm{PM}_{2.5}(\mathrm{~A}), \mathrm{NOx}(\mathrm{B})$, and $\mathrm{Ox}(\mathrm{C})$, and hourly temperature and relative humidity $(\mathrm{D})$ is shown in Figure 1.

\section{Association between hourly concentration of $\mathrm{PM}_{2.5}$ and PEF in the morning}

Figure 2A shows the association between hourly concentration of $\mathrm{PM}_{2.5}$ and PEF at 7 a.m. using the singlepollutant model. A decline in PEF at 7 a.m. was associated with the hourly concentration of $\mathrm{PM}_{2.5}$ during the period from lag 15-hour to lag 4-hour, i.e., the period from 3 p.m. of the previous day to 3 a.m. of the same day in which PEF was measured. The largest effect size was -3.14 liters/minute 
Table 1 Age, height, weight, mean peak expiratory flow (PEF), and number of PEF measurements for each subject

\begin{tabular}{|c|c|c|c|c|c|c|c|c|}
\hline \multirow[t]{2}{*}{ Sex } & \multirow[t]{2}{*}{ Age } & \multirow[t]{2}{*}{ Height } & \multirow[t]{2}{*}{ Weight } & \multicolumn{2}{|c|}{ Number of PEF measurements } & \multicolumn{3}{|c|}{ PEF } \\
\hline & & & & 7 a.m. & 7 p.m. & mean & $\max$ & $\min$ \\
\hline & years & $\mathrm{cm}$ & kg & $\mathrm{n}$ & $\mathbf{n}$ & $\mathrm{I} /$ minute & $\mathrm{I} /$ minute & $\mathrm{I} /$ minute \\
\hline Boy & 8 & 119.0 & 20.3 & 64 & 67 & 217.6 & 329 & 105 \\
\hline Boy & 9 & 133.2 & 33.3 & 58 & 63 & 250.6 & 326 & 138 \\
\hline Boy & 9 & 136.7 & 32.3 & 67 & 70 & 260.9 & 436 & 142 \\
\hline Boy & 10 & 137.0 & 33.3 & 72 & 72 & 305.9 & 434 & 219 \\
\hline Boy & 10 & 138.3 & 28.6 & 68 & 65 & 198.2 & 358 & 130 \\
\hline Boy & 10 & 130.8 & 25.7 & 70 & 67 & 301.9 & 427 & 126 \\
\hline Boy & 11 & 134.5 & 29.3 & 72 & 71 & 232.5 & 349 & 106 \\
\hline Boy & 11 & 145.3 & 35.9 & 77 & 74 & 288.0 & 415 & 123 \\
\hline Boy & 12 & 163.0 & 53.7 & 65 & 66 & 473.1 & 669 & 386 \\
\hline Boy & 12 & 134.5 & 30.2 & 66 & 68 & 296.1 & 382 & 160 \\
\hline Boy & 13 & 160.4 & 46.3 & 77 & 70 & 378.7 & 450 & 281 \\
\hline Boy & 14 & 164.0 & 56.9 & 77 & 74 & 505.3 & 692 & 193 \\
\hline Boy & 15 & 170.5 & 51.7 & 81 & 75 & 399.6 & 530 & 181 \\
\hline Boy & 15 & 163.2 & 60.0 & 68 & 61 & 459.6 & 561 & 301 \\
\hline Girl & 10 & 139.1 & 31.4 & 73 & 72 & 294.2 & 397 & 188 \\
\hline Girl & 12 & 152.5 & 51.5 & 70 & 71 & 351.4 & 474 & 214 \\
\hline Girl & 12 & 147.2 & 41.8 & 73 & 69 & 241.9 & 319 & 145 \\
\hline Mean & 11 & 145.2 & 39.0 & 71 & 69 & 320.9 & & \\
\hline
\end{tabular}

(1/minute) (95\% CI: $-4.09,-2.20)$ for an hourly $\mathrm{PM}_{2.5}$ concentration of $10 \mu \mathrm{g} / \mathrm{m}^{3}$ between 11 p.m. and $12 \mathrm{p} . \mathrm{m}$. on the previous night (lag 7-hour). Some of the significant associations remained even after adjustment for other air pollutants using the multi-pollutant model (Figure 2B and Figure 2C).

\section{Association between hourly concentration of $\mathrm{PM}_{2.5}$ and PEF in the evening}

Figure 3A shows the association between hourly concentration of $\mathrm{PM}_{2.5}$ and $\mathrm{PEF}$ at 7 p.m. using the singlepollutant model. A decline in PEF at 7 p.m. was associated with the hourly concentration of $\mathrm{PM}_{2.5}$ during the period from lag 3-hour to lag 0-hour, i.e., the period from 3 p.m. to 7 p.m. of the same day on which PEF was measured. The largest effect size was -3.06 l/ minute (95\% CI: $-4.72,-1.41)$ for an hourly $\mathrm{PM}_{2.5}$ concentration of $10 \mu \mathrm{g} / \mathrm{m}^{3}$ between 4 p.m. and 5 p.m. (lag 2-hour). This association was also seen during the period from lag 23-hour to lag 12-hour, i.e., the period from 7 p.m. of the previous day to 7 a.m. of the same day in which PEF were measured. Some of these significant associations remained on use of the 2-pollutant model (Figure 3B).

\section{Association between 24-hour concentration of $\mathrm{PM}_{2.5}$ and PEF}

When we estimated the association between 24-hour concentration of $\mathrm{PM}_{2.5}$ and $\mathrm{PEF}$, we observed a significant association in the single-pollutant model in both the morning and evening (-2.96 $1 /$ minute (95\% CI: -4.55 ,

Table 2 Hourly mean concentration of air pollutants

\begin{tabular}{|c|c|c|c|c|c|c|c|c|c|}
\hline & & Morr & & Noc & & Eve & & $\mathrm{Nic}$ & \\
\hline & & (6 a.m. thro & a.m.) & (12 p.m. thro & o.m.) & (6 p.m. thro & o.m.) & (12 a.m. thr & a.m.) \\
\hline & & Mean & (SD) & Mean & (SD) & Mean & (SD) & Mean & (SD) \\
\hline $\mathrm{PM}_{2.5}$ & $\left(\mu \mathrm{g} / \mathrm{m}^{3}\right)$ & 24.0 & (17.6) & 26.9 & (21.4) & 30.0 & (22.0) & 25.8 & (17.6) \\
\hline$O x$ & (ppb) & 8.3 & (6.8) & 23.3 & (12.3) & 13.1 & (9.0) & 9.1 & (7.6) \\
\hline $\mathrm{NO}_{2}$ & $(\mathrm{ppb})$ & 24.0 & (9.4) & 22.2 & (16.0) & 32.6 & $(12.8)$ & 28.3 & $(12.1)$ \\
\hline Temperature & $\left({ }^{\circ} \mathrm{C}\right)$ & 10.1 & (5.6) & 15.9 & $(5.0)$ & 14.2 & (4.6) & 11.6 & (5.1) \\
\hline
\end{tabular}

$\mathrm{PM}_{2.5}$ : Particulate matter with a $50 \%$ cut-off of aerodynamic diameter $\leq 2.5 \mu \mathrm{m}$.

$\mathrm{NO}_{2}$ : Nitrogen dioxide.

Ox: Photochemical oxidants. 
Table 3 Correlation among air pollutants

\begin{tabular}{lcccr}
\hline & \multicolumn{4}{c}{ Correlation coefficient } \\
\cline { 2 - 5 } & Morning & Noon & Evening & Night \\
\cline { 2 - 6 } & (6 a.m. through 7 a.m.) & (12 p.m. through 1 p.m.) & (6 p.m. through 7 p.m.) & (12 a.m. through 1 a.m.) \\
\hline $\mathrm{PM}_{2.5}-\mathrm{Ox}$ & -0.44 & -0.24 & -0.27 & -0.40 \\
\hline $\mathrm{NO}_{2}-\mathrm{PM}_{2.5}$ & 0.54 & 0.78 & 0.62 & 0.56 \\
\hline $\mathrm{Ox}-\mathrm{NO}_{2}$ & -0.74 & -0.53 & -0.68 & -0.72 \\
\hline
\end{tabular}

$\mathrm{PM}_{2.5}$ : Particulate matter with a $50 \%$ cut-off of aerodynamic diameter $\leq 2.5 \mu \mathrm{m}$.

$\mathrm{NO}_{2}$ : Nitrogen dioxide.

Ox: Photochemical oxidants.

-1.37 ) and $-4.42 \mathrm{l} / \mathrm{minute}(95 \% \mathrm{CI}:-7.11,-1.73)$ for a 24-hour mean $\mathrm{PM}_{2.5}$ concentration of $10 \mu \mathrm{g} / \mathrm{m}^{3}$, respectively) (Table 4). These associations were also seen with the 2-pollutant and 3-pollutant models, but without statistical significance except for the 2-pollutant model.

\section{Association between hour concentrations of the other pollutants and PEF}

We also show the association between hourly concentrations of other pollutants such as $\mathrm{NO}_{2}$ and $\mathrm{Ox}$ and PEF using the single-pollutant model in Figure 4. Increasing hourly concentrations of $\mathrm{NO}_{2}$ were positively associated with declines in both morning and evening $\mathrm{PEF}$, while increasing hourly concentrations of Ox were preventively associated with declines in both morning and evening PEF. When we used the 3-pollutant model, the association between $\mathrm{Ox}$ and PEF disappeared. In contrast, the association between $\mathrm{NO}_{2}$ and PEF partially remained, even after adjustment for $\mathrm{PM}_{2.5}$ and Ox (Figure 5).

\section{Discussion}

In this study in hospitalized children with severe asthma, we found a significant association between some lags of $\mathrm{PM}_{2.5}$ and PEF using hourly concentrations of $\mathrm{PM}_{2.5}$ in a single pollutant model. Some of these significant associations remained after adjustment for other air pollutants. We also found an association between 24-hour mean concentration of $\mathrm{PM}_{2.5}$ and PEF.

One strength of this study was that PEF was measured using an electronic spirometer under the guidance of trained nurses. PEF measurements might therefore have been more accurate than in previous studies, in most of which PEF was self-measured using a peak flow meter. In addition, our subjects were under long-term hospitalization and therefore likely maintained a more regular schedule than non-hospitalized subjects, which likely minimized the effects of unknown or unmeasurable confounders.

In this study, we found an association between $\mathrm{PM}_{2.5}$ and PEF in both the morning and evening using a single pollutant and a 2-pollutant model. However, this
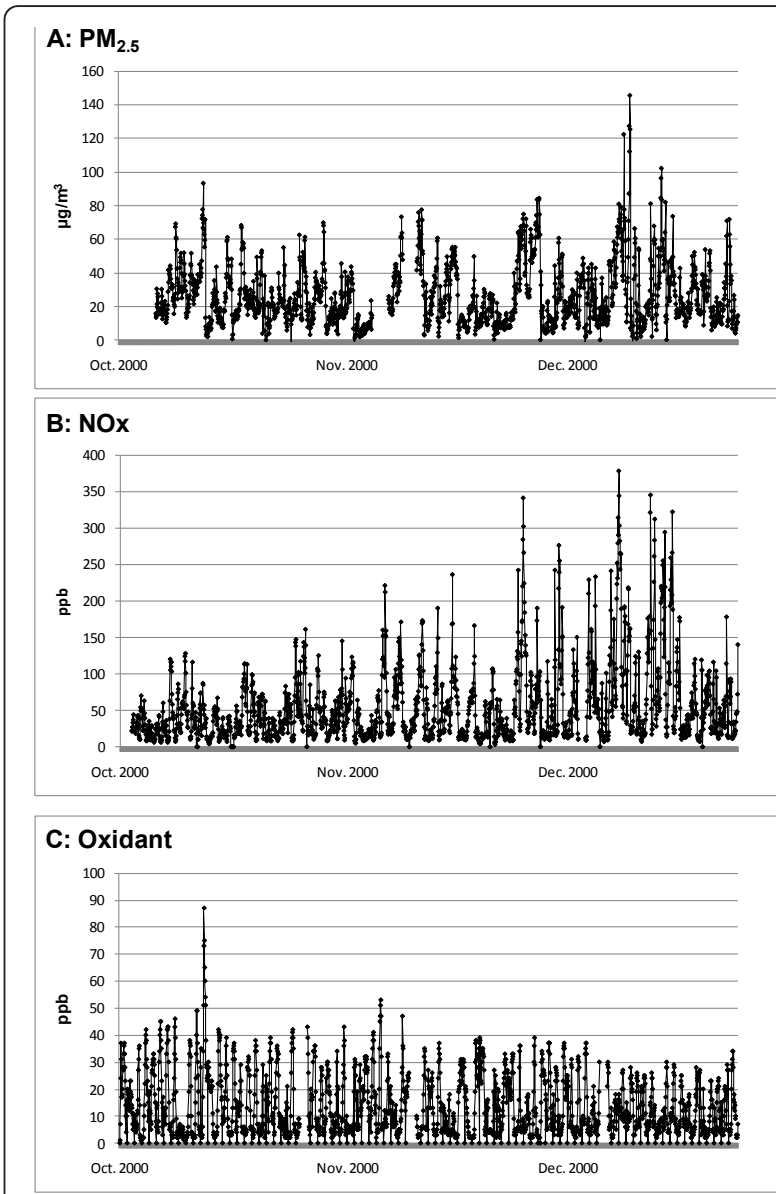

D: Temperature

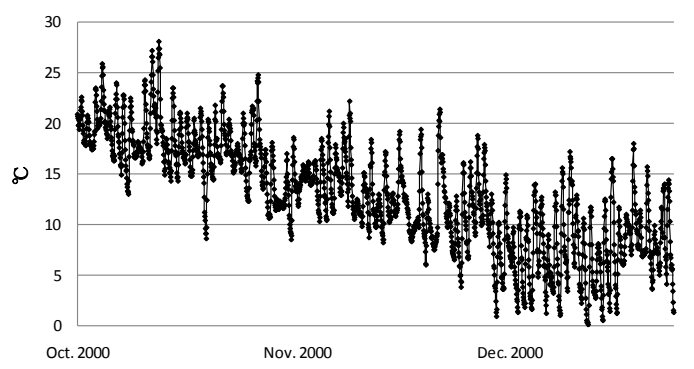

Figure 1 Hourly concentration of air pollutants and hourly temperature from October 1, 2000 through December 24, 2000. A: $P_{2.5}$ B: NOx C: Ox D: Temperature. 

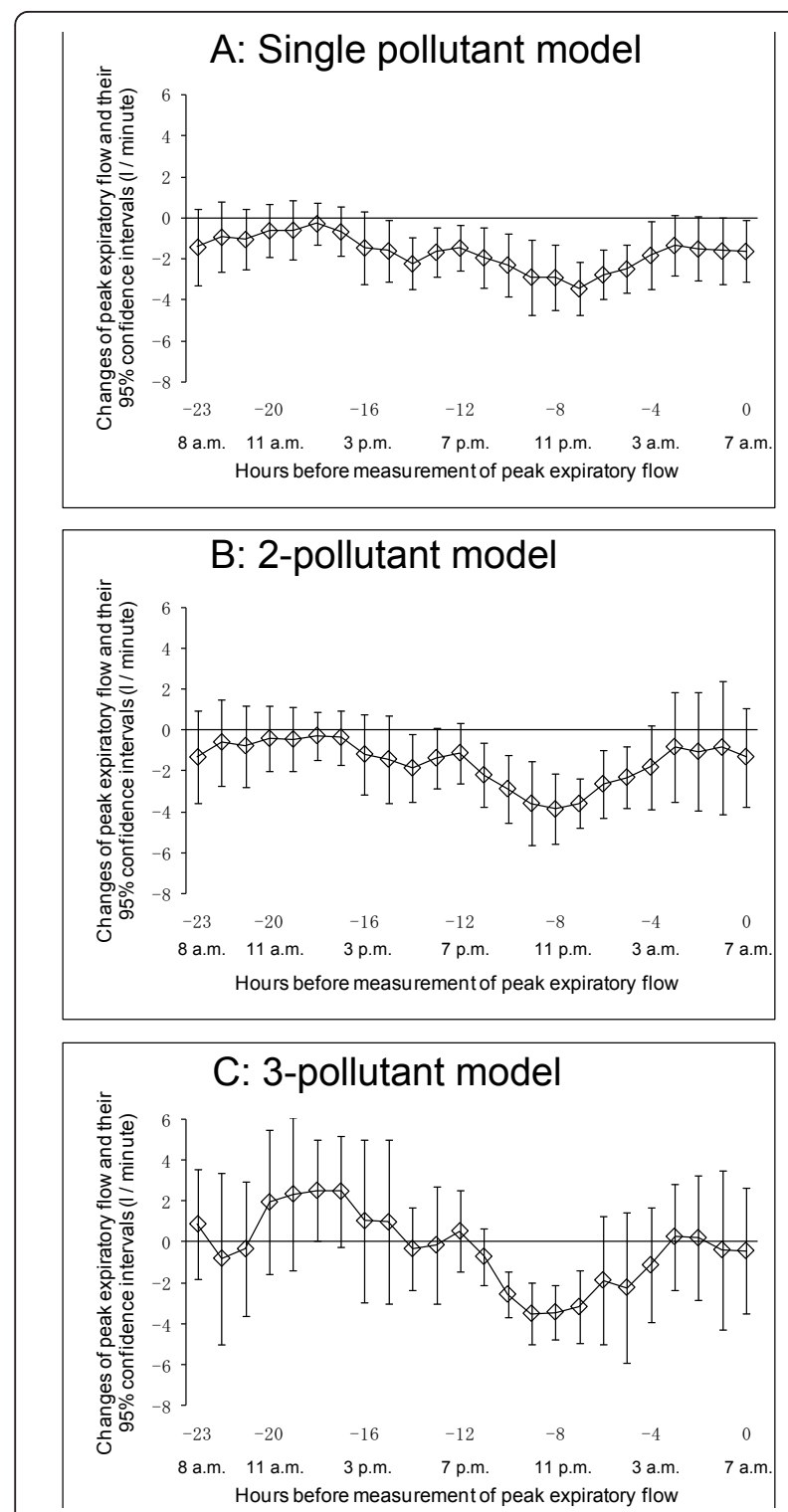

Figure 2 Association between PEF measured in the morning at 7 a.m. and hourly concentration of $\mathbf{P M}_{2.5}$. Lagged-hour exposures of up to 24 hours were examined. The mean differences and 95\% confidence intervals in PEF per $10 \mu \mathrm{g} / \mathrm{m}^{3}$ increases in $\mathrm{PM}_{2.5}$ were estimated. A: Single-pollutant model adjusted for age, sex, height, day of the week, temporal trends, and temperature. B: 2-pollutant model adjusted for age, sex, height, day of the week, temporal trends, photochemical oxidants, and temperature. C: 3-pollutant model adjusted for age, sex, height, day of the week, temporal trends, nitrogen dioxide, photochemical oxidants, and temperature.

association was not stable using a 3-pollutant model. Because the effect size of the results were closely similar, the reason for the loss of a significant association was likely the strong correlation between $\mathrm{NO}_{2}$ and $\mathrm{PM}_{2.5}$ in the evening and $\mathrm{NO}_{2}$ and $\mathrm{Ox}$ in the morning (Table 3).

Similarly, we also found an association between 24-hour $\mathrm{PM}_{2.5}$ and PEF in both the morning and evening
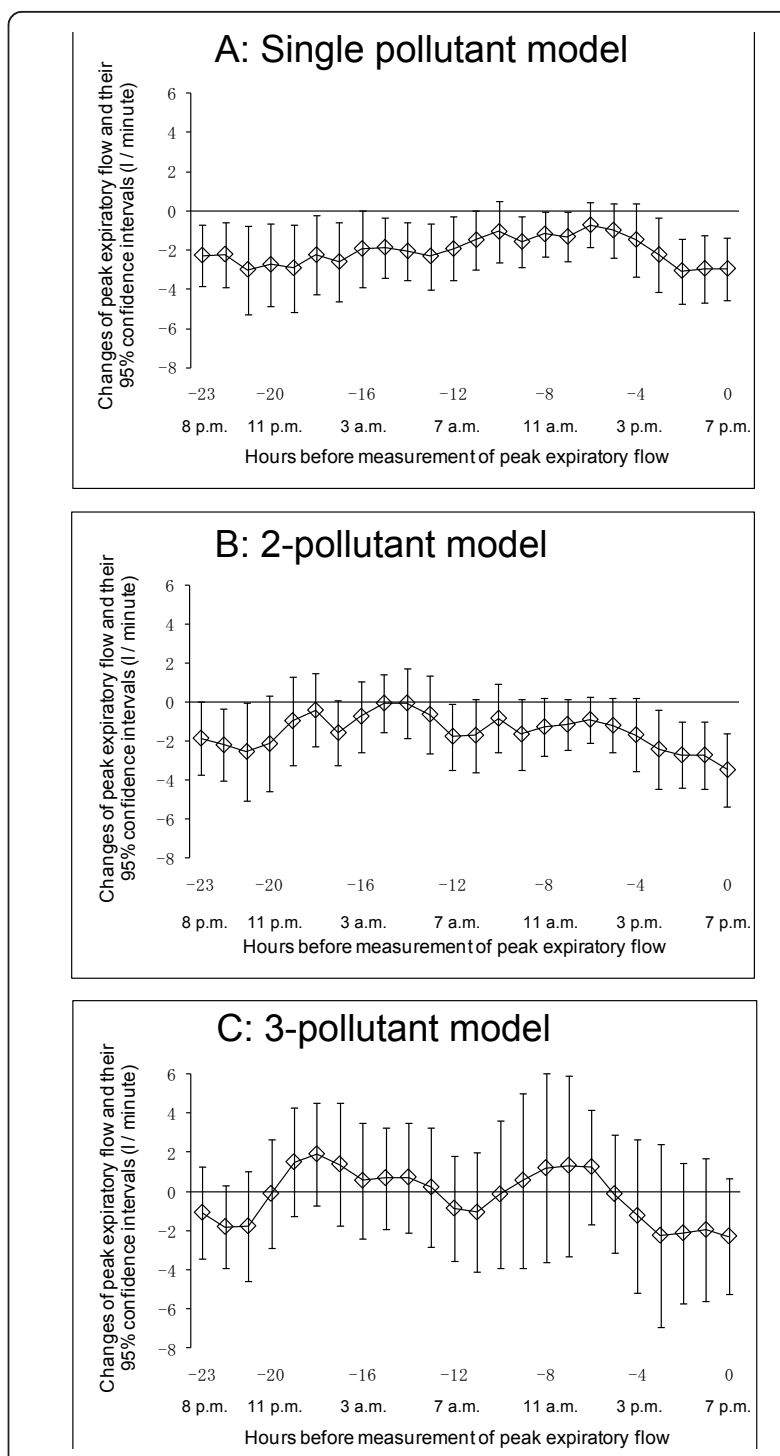

Figure 3 Association between PEF measured in the evening at 7 p.m. and hourly concentration of $\mathrm{PM}_{2.5}$. Lagged-hour exposures of up to 24 hours were examined. Mean differences and $95 \%$ confidence intervals in PEF for $10 \mu \mathrm{g} / \mathrm{m}^{3}$ increases in $\mathrm{PM}_{2.5}$ were estimated. A: Single-pollutant model adjusted for age, sex, height, day of the week, temporal trends, and temperature. B: 2-pollutant model adjusted for age, sex, height, day of the week, temporal trends, photochemical oxidants, and temperature. C: 3-pollutant model adjusted for age, sex, height, day of the week, temporal trends, nitrogen dioxide, photochemical oxidants, and temperature.

using the single pollutant model. We speculate that the weakened association between 24-hour $\mathrm{PM}_{2.5}$ and PEF using the 2- and 3-pollutant models might have also been affected by the high correlation among air pollutants.

In this study the effect size of the results for morning and evening PEF were closely similar. Several previous studies have examined the association between PM and 
Table 4 Change in peak expiratory flow (PEF) for a 24-hour concentration of $\mathrm{PM}_{2.5}$ of $10 \mu / \mathrm{m}^{3}$

\begin{tabular}{|c|c|c|c|c|}
\hline & Mo & & Eve & \\
\hline & (PEF a & & (PEF at & \\
\hline & Changes (I/minute) & $(95 \% \mathrm{Cl})$ & Changes (I/minute) & $(95 \% \mathrm{Cl})$ \\
\hline Single pollutant model* & -2.96 & $(-4.55,-1.37)$ & -4.42 & $(-7.11,-1.73)$ \\
\hline 2-pollutant modelt & -2.52 & $(-4.60,-0.44)$ & -3.51 & $(-6.37,-0.65)$ \\
\hline 3-pollutant modelf & -1.59 & $(-3.61,0.43)$ & -2.36 & $(-7.59,2.86)$ \\
\hline
\end{tabular}

morning PEF/evening PEF. A previous panel study in children with chronic respiratory symptoms from March through April in Finland showed that the changes in morning and evening PEF for the inter-quartile range $\left(14 \mu \mathrm{g} / \mathrm{m}^{3}\right)$ of $\mathrm{PM}_{2.5}$ on the previous day were $-1.06 \mathrm{l} /$ minute $(\mathrm{p}<0.05)$ and $-0.43 \mathrm{l} /$ minute (not statistically significance [N.S.]), respectively [7]. With respect to other PM, such as suspended PM (SPM), which is the concentration of PM with a $100 \%$ cut-off aerodynamic diameter of $\leq 10 \mu \mathrm{m}$; or $\mathrm{PM}_{10}$, which is the concentration of PM with a $50 \%$ cut-off aerodynamic diameter of $\leq 10$ $\mu \mathrm{m}$, their association with PEF has also been shown to be strong in the morning. A panel study of children with chronic respiratory symptoms in the Netherlands showed that the changes in morning and evening PEF for $10-\mu \mathrm{g} / \mathrm{m}^{3}$ increases in $\mathrm{PM}_{10}$ were $-0.41 \mathrm{l} /$ minute $(\mathrm{p}<$ 0.05 ) and $-0.28 \mathrm{l} /$ minute (N.S.), respectively, in children in winter [8]. A panel study of Mexican children with mild asthma showed that changes in morning and evening PEF for $20-\mu \mathrm{g} / \mathrm{m}^{3}$ differences in $\mathrm{PM}_{10}$ were $-1.37 \mathrm{l} /$ minute (N.S.) and $-0.53 \mathrm{l} /$ minute (N.S.), respectively, in April through July and November through February [9]. A panel study of children with asthmatic symptoms in Finland showed that the changes in morning and evening PEF for the inter-quartile range $\left(13 \mu \mathrm{g} / \mathrm{m}^{3}\right)$ of $\mathrm{PM}_{10}$ on the same day were $-0.73 \mathrm{l} / \mathrm{minute}$ (N.S.) and $-0.09 \mathrm{l} / \mathrm{min}$ ute (N.S.), respectively, from February through April [10]. A panel study of children with chronic respiratory symptoms in Finland showed that the changes in morning and evening PEF for the inter-quartile range $(31 \mu \mathrm{g} /$ $\mathrm{m}^{3}$ ) of $\mathrm{PM}_{10}$ on the previous day were $-1.01 \mathrm{l} /$ minute $(\mathrm{N}$. S.) and $-0.331 /$ minute (N.S.), respectively, in March through April [7]. On the other hand, A large-scale panel study in European countries examined daily concentrations of $\mathrm{PM}_{10}$ and $\mathrm{PEF}$ in children with chronic respiratory symptoms in winter, and showed changes in morning and evening PEF for $10-\mu \mathrm{g} / \mathrm{m}^{3}$ increases in $\mathrm{PM}_{10}$ of $0.01 \mathrm{l} /$ minute (N.S.) and $-0.06 \mathrm{l} /$ minute $(\mathrm{p}<$ $0.05)$, respectively [11]. The authors speculated that results patterns on morning/evening PEF changes which were associated with air pollution were not clear. In most of these previous studies, the associations were evaluated using a single pollutant model.

A Japanese panel study showed that the change in morning PEF for a $10-\mu \mathrm{g} / \mathrm{m}^{3}$ increase in the 3 -hour concentration of SPM measured at 2 a.m. to 5 a.m. on the same day was $-0.76 \mathrm{l} /$ minute $(\mathrm{p}<0.05)$ among children with asthma in April through September using a single pollutant model [4]. These results were robust after adjustment for $\mathrm{NO}_{2}$ and ozone. This study also found that declines in evening PEF were weakly associated with increasing 3-hour concentrations of SPM, albeit without statistical significance. On the other hand, when the association was examined in October through March, an increase in SPM was not associated with a decline in PEF. We speculate that the reason for this is the high correlation among air pollutants in the winter.

It seems that both morning and evening PEF were associated with concentrations of $\mathrm{PM}_{2.5}$ from 5 p.m. to 5 a.m. (Figure $2 \mathrm{~A}$ and Figure $3 \mathrm{~A}$ ). We speculate that one reason for this is that exposure measurement during the night would be more representative of exposure to air pollutants, because this time point might be less influenced by the children's activity or the chance of local sources of pollution such as automobile traffic outside the window where the monitor placed. Another reason might be differences in correlations among air pollutants at night from those in the day (Table 3).

With respect to other pollutants, increasing hourly concentrations of $\mathrm{NO}_{2}$ were positively associated with declines in PEF using the single-pollutant model, and increasing hourly concentrations of Ox were preventively associated with declines in PEF. Use of the 3 -pollutant model resulted in the loss of the association between $\mathrm{Ox}$ and PEF. On the other hand, the association between $\mathrm{NO}_{2}$ and PEF remained, even after adjusted for $\mathrm{PM}_{2.5}$ and $\mathrm{Ox}$. One explanation of these results is the negative correlation between $\mathrm{NO}_{2}$ and $\mathrm{Ox}$ (Table 3). Because high correlations were also seen between $\mathrm{NO}_{2}$ and $\mathrm{PM}_{2.5}(\mathrm{r}=0.54-0.76)$ (Table 3), results from multi-pollutant model were 

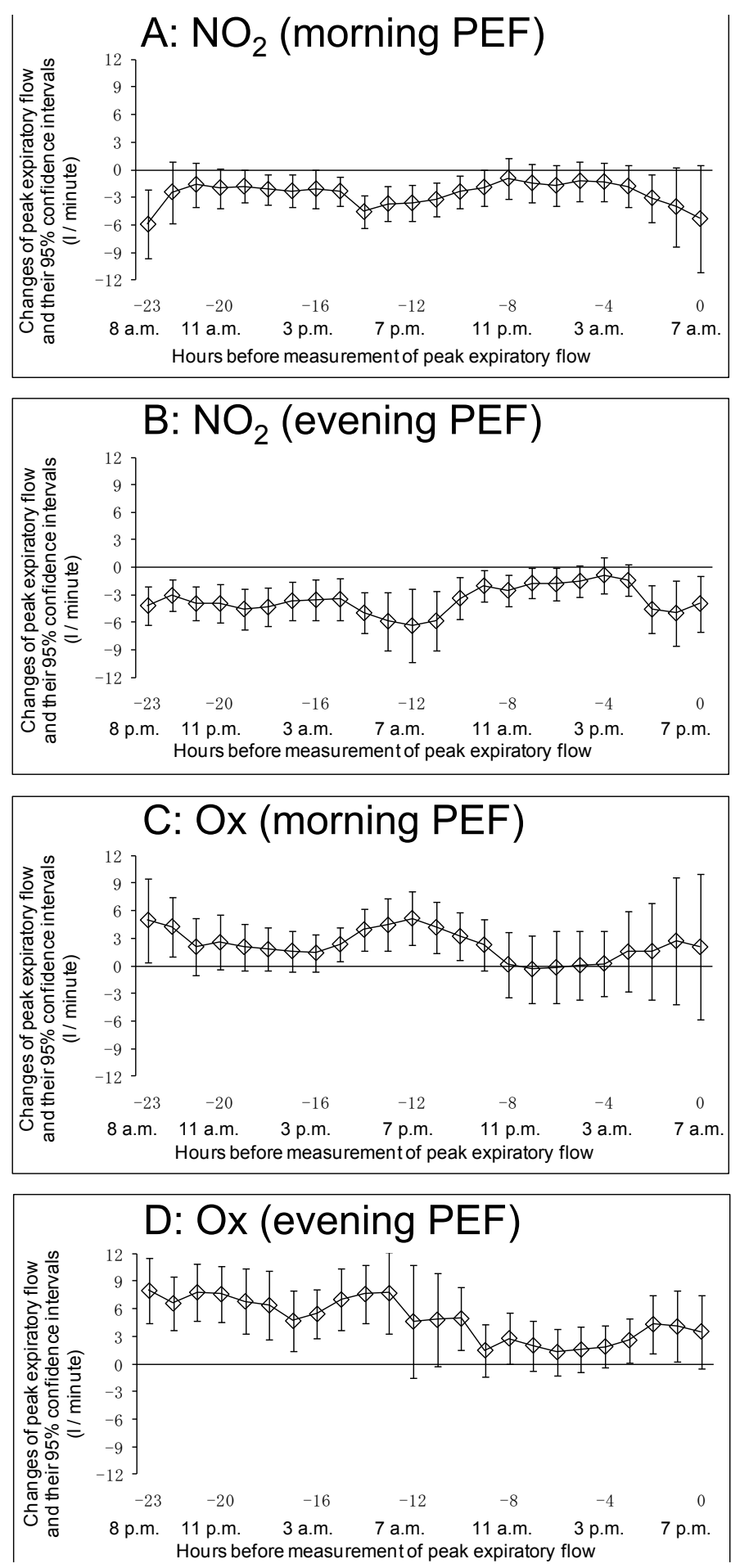

Figure 4 Association between PEF and hourly concentration of other pollutants $\left(\mathrm{NO}_{2}\right.$ and $\left.\mathrm{Ox}\right)$ using single-pollutant model. Laggedhour exposures of up to 24 hours were examined. Mean differences and 95\% confidence intervals in PEF for 10 ppb increases in $\mathrm{NO}_{2} / \mathrm{Ox}$ were estimated using single pollutant model adjusted for age, sex, height, day of the week, temporal trends, and temperature. A: Association between PEF measured in the morning at 7 a.m. and hourly concentration of $\mathrm{NO}_{2}$. B: Association between PEF measured in the evening at 7 p.m. and hourly concentration of $\mathrm{NO}_{2}$. C: Association between PEF measured in the morning at 7 a.m. and hourly concentration of Ox. D: Association between PEF measured in the evening at 7 p.m. and hourly concentration of Ox. 

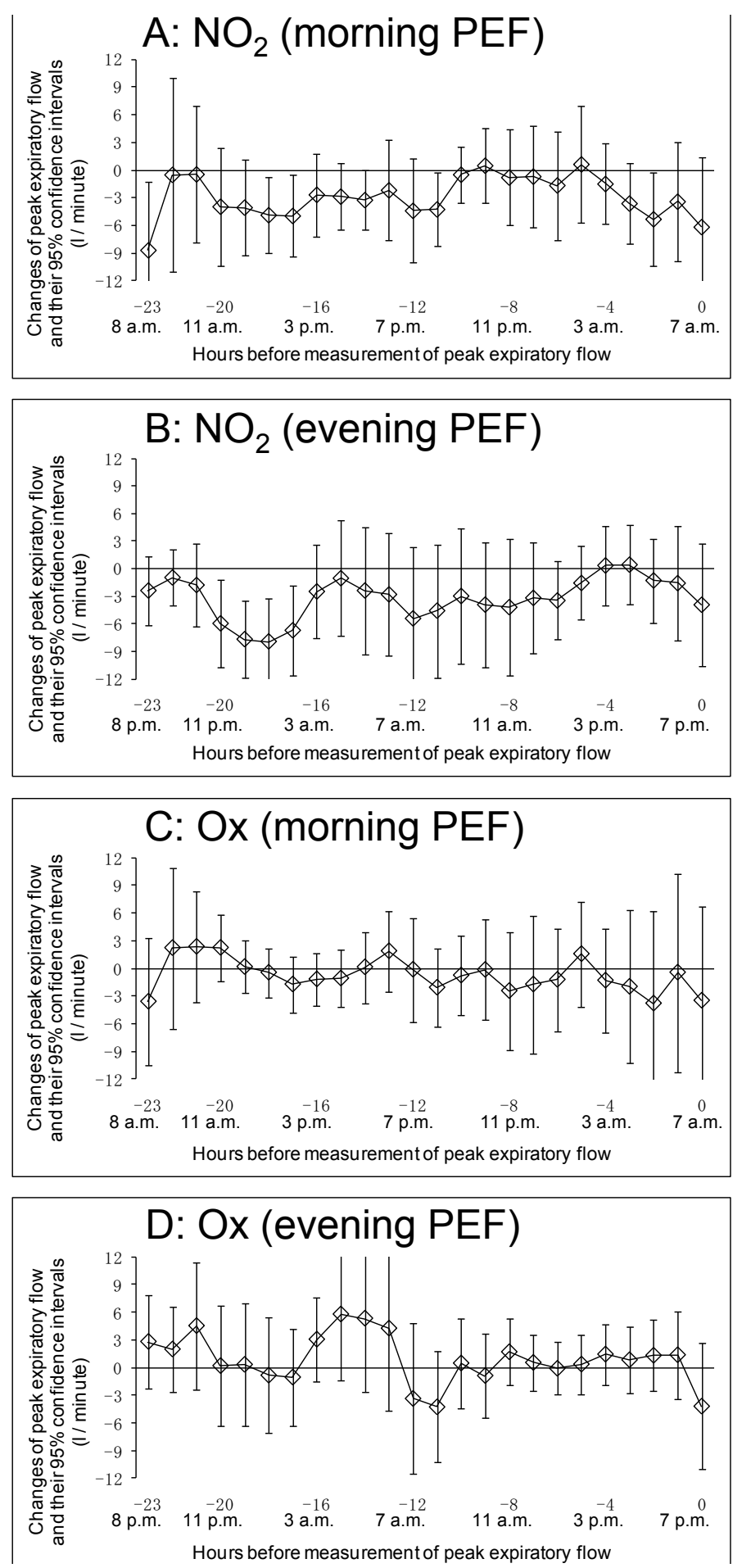

Figure 5 Association between PEF and hourly concentration of other pollutants $\left(\mathrm{NO}_{2}\right.$ and $\left.\mathrm{Ox}\right)$ using 3-pollutant model. Lagged-hour exposures of up to 24 hours were examined. Mean differences and $95 \%$ confidence intervals in PEF for 10 ppb increases in $\mathrm{NO}_{2} / \mathrm{O} \times$ were estimated using 3-pollutant model adjusted for age, sex, height, day of the week, temporal trends, and temperature. A: Association between PEF measured in the morning at $7 \mathrm{a} . \mathrm{m}$. and hourly concentration of $\mathrm{NO}_{2}$. B: Association between PEF measured in the evening at 7 p.m. and hourly concentration of $\mathrm{NO}_{2}$. C: Association between PEF measured in the morning at 7 a.m. and hourly concentration of Ox. D: Association between PEF measured in the evening at 7 p.m. and hourly concentration of Ox. 
likely affected by multicollinearity, and it was difficult to clarify the independent effects of $\mathrm{NO}_{2}$ and $\mathrm{PM}_{2.5}$ on PEF. Both might have come from the same sources and been subject to the same meteorological conditions. A comprehensive understanding of the complex association between air pollutants and PEF awaits further study.

\section{Limitations}

The results of this study should be viewed cautiously for several reasons. First, the small sample size and restriction of patients to those with severe asthma may have produced problems with external validity in the selection of subjects. The subjects of this study were hospitalized children with poorly controlled asthma and frequent exacerbations. Generalization of these results to other populations, such as children with mild asthma or hospitalized children with other diseases is likely difficult. Second, ambient concentrations of air pollution might have acted as surrogate measures of exposure to other agents or specific pollution sources that were, in fact, responsible for the observed association between $\mathrm{PM}_{2.5}$ and PEF. Third, we assessed the exposure level of air pollutants using data from the nearest fixed monitoring station from the hospital, and not individual exposure. Exposure level might therefore be biased. However, many studies in this field use air pollutant data from fixed monitoring stations. Subjects of this study were hospitalized children. During hospitalization, they had the opportunity to expose themselves to outdoor air. They went to school twice a day, morning and afternoon. The school was next to the hospital, requiring them to walk outdoors, and they also played outdoors after school. The hospital was not equipped with a central air conditioning system at the time the study was conducted, and hospital rooms were usually ventilated by opening windows. However, these individual exposure-related conditions were not quantified. Fourth, the model assumed that the effects of $\mathrm{PM}_{2.5}$ would be linear over the observed range of exposure.

In this study, we tested the association between air pollutants and PEF using multiple time lags in both single and multiple pollutant models, raising the possibility of issues with repeated significance testing. We did not attempt to counter this potential problem, however, considering instead that the elevated risks of air pollutants in this study should be demonstrated to the greatest extent possible in accordance with the precautionary principle.

\section{Policy implications}

The subjects were treated in hospital with medications which included inhaled corticosteroids. Even in this situation, we found large changes in PEF with increased $\mathrm{PM}_{2.5}$. Efforts to prevent the exacerbation of asthma due to air pollution should focus on air-quality standards for particulate matter based on not only on 24-hour mean concentrations but also hourly data.

\section{Conclusion}

Among hospitalized children with severe asthma, increased hourly concentrations of $\mathrm{PM}_{2.5}$ were associated with a decrease in PEF.

\section{Abbreviations}

$\mathrm{Cl}$ : confidence interval; GEE: Generalized Estimating Equations; $\mathrm{NO}_{2}$ : nitrogen dioxide; Ox: photochemical oxidants; PEF: peak expiratory flow; PM: particulate matter; $\mathrm{PM}_{10}$ : particulate matter with a $50 \%$ cut-off aerodynamic diameter of $\leq 10 \mu \mathrm{m} ; \mathrm{PM}_{2.5}$ : particulate matter with a $50 \%$ cut-off aerodynamic diameter of $\leq 2.5 \mu \mathrm{m}$; SPM: suspended particulate matter.

\section{Acknowledgements}

This study was funded by the Japanese Ministry of the Environment.

\section{Author details}

${ }^{1}$ Department of Epidemiology and Healthcare Research, Kyoto University School of Public Health, Yoshidakonoe-cho, Sakyo-ku, Kyoto, Japan.

${ }^{2}$ Department of Public Health, Hyogo College of Medicine, 1-1 Mukogawacho, Nishinomiya, Japan. ${ }^{3}$ Department of Respirology, Graduate School of Medicine, Chiba University, 1-8-1 Inohana, Chuo-ku, Chiba, Japan. ${ }^{4}$ Environmental Health Science Division, National Institute for Environmental Studies, 16-2 Onogawa, Tsukuba, Japan. ${ }^{5}$ Department of Pediatrics, Shimoshizu National Hospital, 934-5 Shikawatashi, Yotsukaido, Japan.

\section{Authors' contributions}

MS and TN designed and initiated this study. MS, MA, HW and TN were responsible for collecting the clinical data. SY and HN were responsible for creating database and statistical analysis. SY and MS were responsible for writing the draft version of manuscript. All authors commented on approved the final manuscript.

\section{Competing interests}

The authors declare that they have no competing interests.

Received: 8 October 2010 Accepted: 10 March 2011

Published: 10 March 2011

\section{References}

1. United States Environmental Protection Agency: Integrated Science Assessment for Particulate Matter (Final Report) 2009 [http://cfpub.epa.gov/ ncea/cfm/recordisplay.cfm?deid=216546], [Online] Available at: Accessed on October 8, 2010.

2. Ward DJ, Ayres JG: Particulate air pollution and panel studies in children: a systematic review. Occup Environ Med 2004, 61:e13.

3. Pope CA, Dockery DW: Acute health effects of PM10 pollution on symptomatic and asymptomatic children. Am Rev Respir Dis 1992, 145:1123-1128.

4. Odajima $H$, Yamazaki S, Nitta H: Decline in peak expiratory flow according to hourly short-term concentration of particulate matter in asthmatic children. Inhal Toxicol 2008, 20:1263-1272.

5. Shoji H, Tsukatani T: Statistical model of air pollutant concentration and its application to the air quality standards. Atmos Environ 1973, 7:485-501.

6. Liang KY, Zenger SL: Longitudinal data analysis using generalized linear models. Biometrika 1986, 73:13-22.

7. Tiittanen P, Timonen KL, Ruuskanen J, Mirme A, Pekkanen J: Fine particulate air pollution, resuspended road dust and respiratory health among symptomatic children. Eur Respir J 1999, 13:266-273.

8. Roemer W, Hoek G, Brunekreef B: Effect of ambient winter air pollution on respiratory health of children with chronic respiratory symptoms. Am Rev Respir Dis 1993, 147:118-124.

9. Romieu I, Meneses F, Ruiz S, Huerta J, Sienra JJ, White M, Etzel R, Hernandez M: Effects of intermittent ozone exposure on peak expiratory 
flow and respiratory symptoms among asthmatic children in Mexico City. Arch Environ Health 1997, 52:368-376.

10. Pekkanen J, Timonen KL, Ruuskanen J, Reponen A, Mirme A: Effects of ultrafine and fine particles in urban air on peak expiratory flow among children with asthmatic symptoms. Environ Res 1997, 74:24-33.

11. Roemer W, Hoek G, Brunekreef B, Haluszka J, Kalandidi A, Pekkanen J: Daily variations in air pollution and respiratory health in a multicentre study: the PEACE project. Pollution Effects on Asthmatic Children in Europe. Eur Respir J 1998, 12:1354-1361.

doi:10.1186/1476-069X-10-15

Cite this article as: Yamazaki et al.: Effect of hourly concentration of particulate matter on peak expiratory flow in hospitalized children: A panel study. Environmental Health 2011 10:15.

\section{Submit your next manuscript to BioMed Central} and take full advantage of:

- Convenient online submission

- Thorough peer review

- No space constraints or color figure charges

- Immediate publication on acceptance

- Inclusion in PubMed, CAS, Scopus and Google Scholar

- Research which is freely available for redistribution

Submit your manuscript at www.biomedcentral.com/submit 